\title{
تنافسية الصادرات المصرية في اسواق دول القرن الافريقي
}

$$
\text { فيصل عيد العرادة }
$$

طالب دكتوراه، معهد البحوث والدراسات الأفريقية ودول حوض النيل - جامعة أسوان

داليا حامد الشويخ

أستاذ الاقتصاد الزراعى، جامعة أسيوط

$$
\text { جمال حسن كامل }
$$

مدرس الاقتصاد الزراعى، جامعة الوادى الجديد 


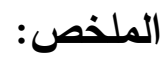

استهدف هذا البحث دراسـة وتحليل مؤشرات القدرة التنافسية للصـادرات المصرية فى أسـواق دول القرن الأفريقى، والتقدير القياسي لأهـم محددات القدرة التتافسية على صـادرات تلك السلح، ونسب تأثير كل محدد على صـادرات تلك السلح، الأمر الذي يساعد في وضع استراتيجية لصـادرات مصر من هذه السلع تساعد على زيادة قدرتها التنافسية. كلمات مفتاحية: تتافسية الصادرات المصرية، في اسواق دول القرن الافريقي مقدمة: لم تكن مصر بعيدة عن منطقة دول القرن الأفريقى حيث كانت دائماً تحظى باهمية كبيرة على اجندة السياسة الخارجية المصرية لما تتمتع به تلك الدول من اهمية على المستوى الدولى والاقليمى، وكذا بعد تولى جمهورية مصر العربية رئاسة الاتحاد الافريقى هذا فضلاً عن دورها كدولة رائدة فى المنطقة، وعلى الجانب الاقتصادى والتجارى تم توقيع مذكرات تفاهم لتعميق العلاقات الثنائية من خلال عقد اللقاءات رفيعة المستوى بين أصحاب القرار ، وذلك بهدف التنسيق على كافة الاصعدة وتدعيم الثراكة المستدامة. وتثير بيانات التجارة الخارجية المصرية إلى استحواذ بعض اكبر الاتحادات الدولية خلال الفترة من ^ ...r حتى 9 1.r على نحو Yq\% من حجم 
صادرات مصر للعالم. وكانت اعلى نسبة للصادرات تذهب الى اسيا بنسبة بلغت حوالى ب.rی\% تلاها الاتحاد الاوربى بنسبة بلغت نحو rr\% ثم الاتحاد الاقريقى

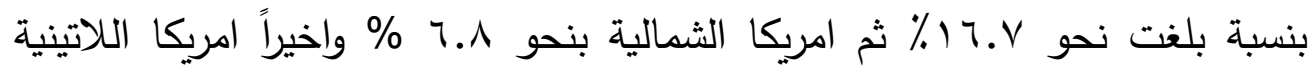
بنسبة بلغت حوالى ؟. ٪\%، وعلى مستوى العالم تقدر نسبة صادرات مصر لدول القرن مقارنةً بواردات دول القرن مجتمعة من العالم خلال نفس الفترة بحوالى ؟.ا \% فى حين بلغت النسبة الاجمالية لصادرات مصر لدول القرن مقارنةً بقيمة الصادرات المصرية للعالم بنحو 1. . . \% وهو ما يثير إلى ضعف التبادل التجارى بين مصر ودول القرن الافريقى.

وقد اهتمت الحكومة المصرية بتدعيم القدرة التتافسية للمنتجات الزراعية فى الاسواق المحلية والاسواق العالمية، بهدف الحصول على أكبر حصة ممكنة من تلك الاسواق، وتعتبر إستراتيجية التوسع في أسواق التصدير إستراتيجية طويلة الأجل تهدف إلى توسيع نطاق السوق الخارجى وزيادة الصادرات للدولة على المدى الطويل، وقد اهتمت الدولة المصرية بتدعيم القدرة التتافسية للمنتجات الزراعية فى الاسواق المحلية

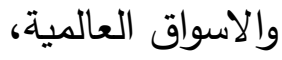

وعليه يجب على مصر بذل الكثير الجهد على المستوى السياسى والدبلوماسى وعلى كافة الاصعدة وفى كافة المحافل حتى يكون لها دور وتمثيل اكبر فى دول 
الاتحاد الافريقى على وجه العموم وفى دول القرن الافريقي على وجه الخصوص نظراً للاهمية الاقتصادية والسياسية والجغرافية والاستراتيجية والامنية التى تمثلها تلك المنطقة لمصر على وجه الخصوص وللعالم على وجه العموم. مشكلة البحث: تثير بيانات التجارة الخارجية المصرية إلى ضعف التبادل التجارى بين مصر ودول القرن الافريقى، بالإضافة إلى انخفاض النصيب السوقي للعديد من السلع الزراعية المصرية في أسواق دول القرن الأفريقى، مما يشير إلى ضعف القدرة التتافسية للصادرات المصرية من السلع، مما يستدعى ضرورة إعادة النظر في خريطة توجيه الصادرات الزراعية المصرية، ومن ثم تتمثل المشكلة فى التساؤل الاتى: هل تمتلك صادرات السلع الزراعية المصرية لدول القرن الأفريقى قدرات تنافسية حقيقية تمكنها من المنافسة فى أسواق دول القرن الأفريقى؟ هدف البحث: يستهدف هذا البحث دراسـة وتحليل مؤشرات القدرة التتافسية للصـادرات المصرية فى أسـواق دول القرن الأفريقى، والتقدير القياسي لأهـ محددات القدرة التتافسية على صـادرات تلك السلح، ونسب تأثير كل محدد على صـادرات تلك السلح، الأمر الذي يساعد في وضع إستراتيجية لصـادرات مصر من هذه السلع تساعد على زيادة قدرتها 
الطريقة البحثية ومصادر البيانات استخدم البحث كل من التحليل الوصفي والكمي لبيانات السلاسل الزمنية خلال الفترة

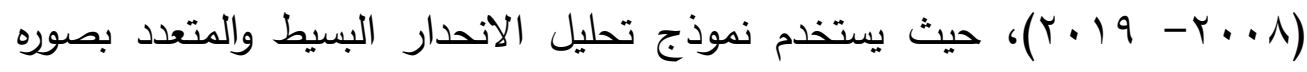
الرياضية المختلفة وذلك لتقدير معدلات النمو والتقدير القياسي لمحدات المركز التنافسي لصادرات السلع المصرية لدول القرنا الأفريقى، بالإضافة إلى تطبيق بعض مؤشرات القدرة التنافسية على المحاصيل التصديرية، واعتمد البحث على في تحقيق

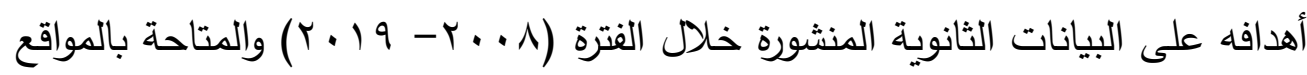
Trade Statistics for المختلفة على شبكة المعلومات الدولية (الإنترنت) مثل International business development Database (UN Comtrade), Trade statistics for international business development (Trade map), العلاقة بموضوع البحث. وفيما يلى عرض لمؤشرات القدرة التنافسية التى تستند عليها الدراسة:

1 - معدل إختراق الأسوق Market Penetration Rate كلما زادت قيمة معدل الإختراق عن الواحد الصحيح، كلما دل ذلك علي زيادة معدل إختراق تلك السلعة موضع الدراسة للسوق. ويتم تقدير معدل إختراق السوق من المعادلة التالية: 


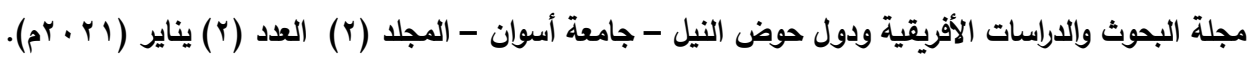

$$
M P R_{i j}=\frac{E X_{i j}}{Q_{i j}+M_{i j}-X_{i j}}
$$

حيث: MPRij = معدل اختراق الدولة i لأهم الأسواق من السلعة ز.

= EXij

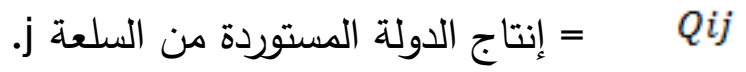

ز = Mij

= Xij

r - r - السعر النسبي:

وهو عبارة عن النسبة بين متوسط سعر تصدير السلعة لأي دولة منافسة إلى متوسط

$$
P a_{j}=\frac{p_{c}}{P_{e}} \quad \text { ســعر تصــدير الدولــة المعنيـة }
$$
ويحسب كالتالي:

حيث: p p p النسبة بـين متوسط سـر تصدير السـلعة لدولـة منافسـة إلى نظيره المصري.

متوسط سعر تصدير السلعة لدولة منافسة. P $_{c}$

متوسط سعر تصدير السلعة للدولة المعنية. P 
ارتفاع قيمة المؤشر عن واحد صحيح تعني زيـادة القدرة التنافسية للدولة المعنية في الأسواق الخارجيـة، وانخفاض قيمـة المؤشر عن واحد صـيح تعني انخفاض القدرة التنافسية لتلك الدولة في الأسواق الخارجية. r- النصيب السوقي: Market Share $M S H j i=\frac{X j c i}{M c w i} \times 100$

حيث أن: MSH

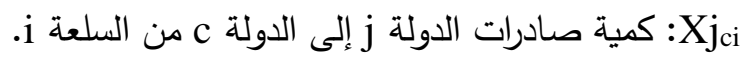

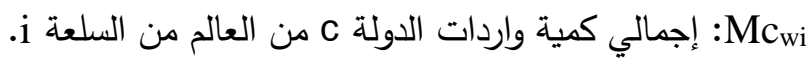
ـ ـ معدل النمو السنوي في كمية الصادرات: ويتم تقديره من قسمة معامل الانحدار في الدالة الخطية على المتوسط السنوي باستخدام بيانات كمية صادر ات السلعة خلال فترة الدر اسة هـ معامل الاستقرار Stability Coefficient:

يقدر هذا المعامل قياس درجـة الوفاء بمتطلبات التصدير، كما يعتبر دليلاً علي الحفاظ علي الأسواق الخارجية للصادرات المصرية والإستمرار فيها وعدم تحول المستوردين إلي أسواق دول أخري، وتقاس قدرة الدولة علي الوفاء بمتطلبات التصدير بناءاً علي إستقرار كمية وسعر وقيمة الصـادرات وفقاً لقيمة معامل الإستقرار النسبي الذي يقاس وفقاً للمعادلة التالية : 
Instability Coefficient $=\frac{\left|\left(y_{i}-\hat{y}_{i}\right)\right|}{\hat{y}_{i}} * 100$

= yi

= القيمة المقدرة للظاهرة موضع الدراسة.

وكلمـا إقتربت قيمـة المعامل من الصفر كلمـا دل ذلك علي إستقرار وثبات المتغير موضع الدراسة، وكلما بعدت عن الصفر كلما دل ذلك علي عدم الإستقرار . צ- الأهمية النسبية للصادرات: أي النسبة بين صـادرات الدولـة المصدرة لأهم الأسواق إلى إجمالي صسادرات الدول المصدرة للسلعة. ويتم حسابه من المعادلة التالية:

$E X M P=\frac{E X M P_{i j}}{E X}$

حيث:

EXMP

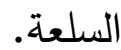

=EXMP EX $X_{j}$ 
كلما زادت قيمة المؤشر للدولة مقارنـة بأي دولتة منافسة كلما أشـار إلى ارتفاع قدرتها التنافسية في السوق والعكس صحيح. - v - vموذج محددات المركز التنافسي: ويمكن التعبير عن هذا النموذج على النحو التالي:

$$
\stackrel{\Lambda}{Y_{i}}=\alpha+B_{1 i} X_{1 i}+B_{2 i} X_{2 i}+B_{3 i} X_{3 i}+B_{4 i} X_{4 i}+B_{5 i} X_{5 i}+e
$$

$$
\text { (t) = } \stackrel{\Lambda}{Y}_{i}
$$

= X

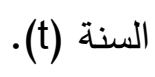

= النسبة بين السعر التصديري للدولة المنافسة إلى نظيره للدولة المعنية لسلعة ما في

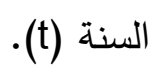

= معامل عدم الاستقرار في الدولة المعنية أو الدول المنافسة لسلعة ما في السنة (t).

= معدل اختراق السوق للدولة المعنية أو الدول المنافسة لسلعة ما في السنة (t). $X_{4}$

$$
\text { (t) = كمية واردات الدولة المستوردة لسلعة ما فى السنة } X_{5}
$$

معاملات التقاطع الصادي والانحدار غير المعلومة. $=, B_{2}, B_{3}, B_{4}, B_{5}, B_{6} B_{1}$ 
بإستقراء بيانات جدول ( ) تبين أن المجموعات السلعية الرئيسية التى تألفت

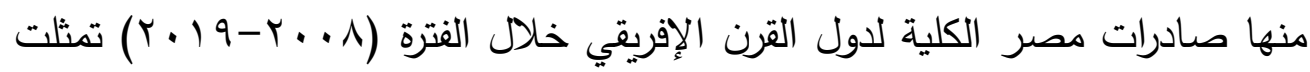
فى 1 مجموعات رئيسية، استحوذت مجموعة "المنتجات الحيوانية والنباتية والمشروبات والتبغ" على نحو 0Y.Y. من متوسط إجمالى صادرات مصر الكلية من المجموعات السلعية، يليها مجموعة" المطاط والجلود والأخثاب والمواد النياتية والورق ومنتجاتة "

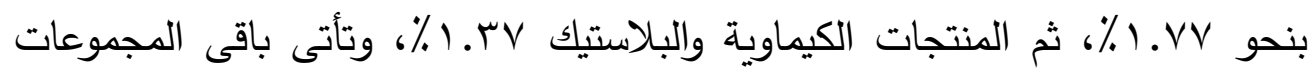

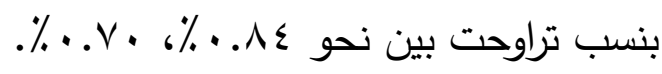
1- التوزيع السلعى لصادرات مصر الكلية لاولة جيبوتي بإستقراء بيانات جدولى (1، r) تبين أن المجموعات السلعية الرئيسية التى

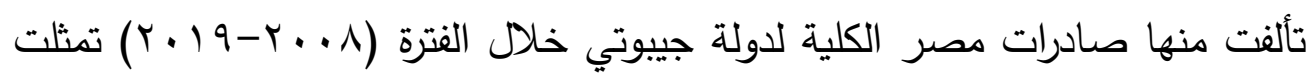
فى ^ مجموعات رئيسية، استحوذت مجموعة " المنتجات المعدنية" على نحو ب . . ٪، 7. 1 ٪ من متوسط إجمالى الصادرات المصرية الكلية من المجموعات السلعية للعالم، متوسط إجمالى الصادرات المصرية الكلية

جدول (1): الأهمية النسبية لصادرات مصر الاجمالية من المجموعات السلعية لدول القرن

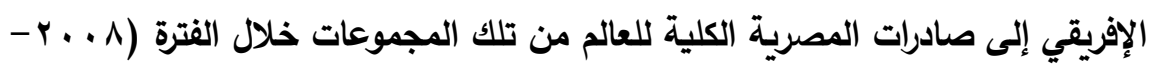

\begin{tabular}{|c|c|c|c|c|c|c|}
\hline & & & & & &.$(r \cdot 19$ \\
\hline$\%$ & المتوسط & الصومال & 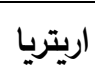 & اثيوبيا & 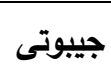 & المجموعة \\
\hline 2.25 & 106.07 & 0.79 & 0.97 & 0.29 & 0.20 & المنتجات الحيوانية والنباتية والمشروبات والتبغ \\
\hline
\end{tabular}




\begin{tabular}{|c|c|c|c|c|c|c|}
\hline 0.18 & 14.33 & 0.00 & 0.04 & 0.11 & 0.03 & الوقود والمنتجات البترولية ومنتجات الصناعات الاستخراجية \\
\hline 1.37 & 54.74 & 0.13 & 0.26 & 0.82 & 0.16 & المنتجات الكيماوية والبلاستيك \\
\hline 1.77 & 11.08 & 0.08 & 0.25 & 1.23 & 0.21 & المطاط والجلود والأخشاب والمواد النياتية والورق ومنتجاتة \\
\hline 0.13 & 3.62 & 0.01 & 0.00 & 0.06 & 0.05 & الخيوط والألياف النسيجية ومنتجات الغزل والنسيج والملابس \\
\hline 0.17 & 3.68 & 0.00 & 0.04 & 0.08 & 0.04 & مصنوعات الرخام والأحجار والخزف والزجاج والمواد المماثلة \\
\hline 0.70 & 15.92 & 0.01 & 0.10 & 0.37 & 0.22 & المنتجات المعدنية \\
\hline 0.84 & 14.64 & 0.01 & 0.04 & 0.61 & 0.19 & الألات والأجهزة الآلية والكهربائية ومعدات النقل وأجزائها \\
\hline
\end{tabular}

من المجموعات السلعية لدول القرن الأفريقى، يليها مجموعة" المطاط والجلود

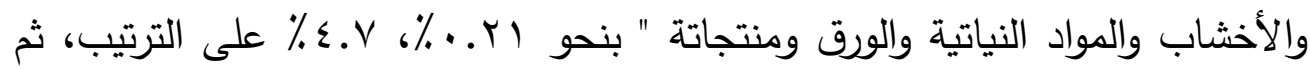

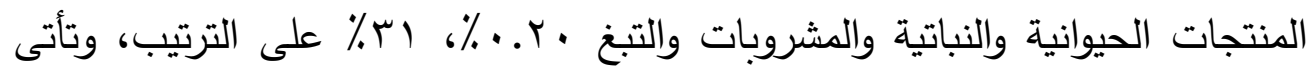
باقى المجموعات بنسب تراوحت بين نحو 9 1. . \%، 1 ـ . ٪. جدول (r): صادرات مصر الاجمالية من المجموعات السلعية لجيبوتى بالمليون دولار خلال الفترة

\begin{tabular}{|c|c|c|}
\hline & & $\cdot(r \cdot 19-r+\cdots)$ \\
\hline$\%$ & المتوسط & 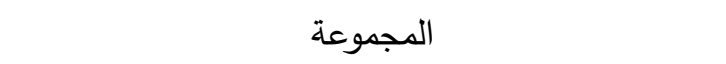 \\
\hline 31.0 & 9.5 & المنتجات الحيوانية والنباتية والمشروبات والتتخ \\
\hline 7.6 & 2.3 & الوقود والمنتجات البترولية ومنتجات الصناعات الاستخراجية \\
\hline 24.7 & 7.5 & المنتجات الكيماوية والبلاستيك \\
\hline 4.7 & 1.4 & المطاط والجلود والأخثاب والمواد النياتية والورق ومنتجاتة \\
\hline 4.0 & 1.2 & الخيوط والألياف النسيجية ومنتجات الغزل والنسيج والملابس \\
\hline 3.4 & 1.0 & مصنوعات الرخام والأحجار والخزف والزجاج والمواد المماثلة \\
\hline 14.6 & 4.5 & المنتجات المعدنية \\
\hline 9.9 & 3.0 & الألات والأجهزة الآلية والكهربائية ومعدات النقل وأجزائها \\
\hline 100.0 & 30.5 & الاجمالى \\
\hline
\end{tabular}

المصدر : حسبت من: Www.comtrade.un.org 


\section{r - التوزيع السلعى لصادرات مصر الكلية لاولة أثيوبيا}

بإستقراء بيانات جدولى (1، r) تبين أن المجموعات السلعية الرئيسية التى

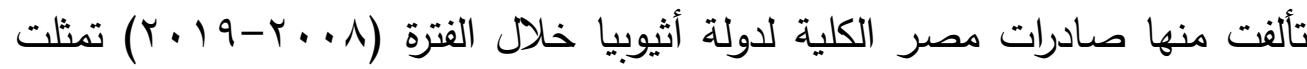
فى 1 مجموعات رئيسية بالاضافة إلى، استحوذت مجموعة " المطاط والجلود والأخشاب والمواد النياتية والورق ومنتجاتة " على نحو سץ. ٪، 9٪ من متوسط إجمالى الصادرات المصرية الكلية من المجموعات السلعية للعالم، متوسط إجمالى الصادرات المصرية الكلية من المجموعات السلعية لدول القرن الأفريقى، يليها مجموعة

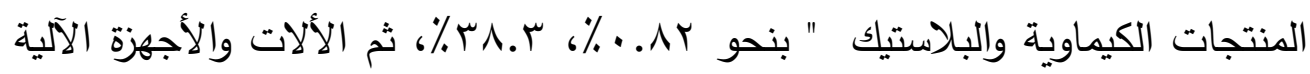

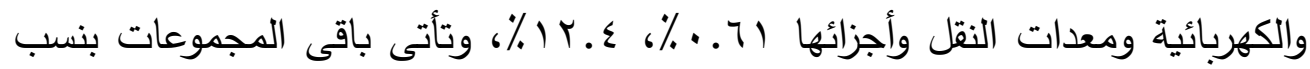

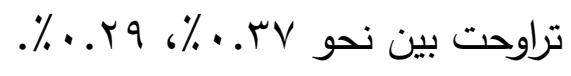

جدول (r): صادرات مصر الاجمالية من المجموعات السلعية لأثيوبيا بالمليون دولار خلال الفترة

$$
\cdot(r \cdot 19-r \cdot . \wedge)
$$

\begin{tabular}{|c|c|c|}
\hline$\%$ & المتوسط & 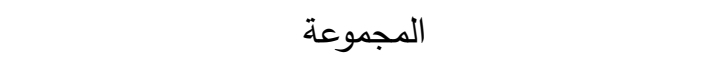 \\
\hline 15.9 & 13.52 & المنتجات الحيوانية والنباتية والمشروبات والتتخ \\
\hline 10.2 & 8.64 & الوقود والمنتجات البترولية ومنتجات الصناعات الاستخراجية \\
\hline 38.3 & 32.64 & المنتجات الكيماوية والبلاستيك \\
\hline 9.0 & 7.69 & المطاط والجلود والأخشاب والمواد النياتية والورق ومنتجاتة \\
\hline 2.1 & 1.82 & الخيوط والألياف النسيجية ومنتجات الغزل والنسيج والملابس \\
\hline 2.1 & 1.81 & مصنوعات الرخام والأحجار والخزف والزجاج والمواد المماثلة \\
\hline 10.0 & 8.48 & 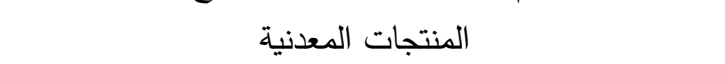 \\
\hline 12.4 & 10.54 & الألات والأجهزة الآلية والكهربائية ومعدات النقل وأجزائها \\
\hline
\end{tabular}




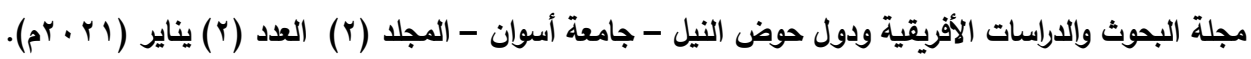

$100.0 \quad 85.15$

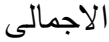

المصدر: حسبت من: www.comtrade.un.org

ب- التوزيع السلعى لصادرات مصر الكلية لدولة إريتريا

بإستقراء بيانات جدولى (1، ؟) تبين أن المجموعات السلعية الرئيسية التى

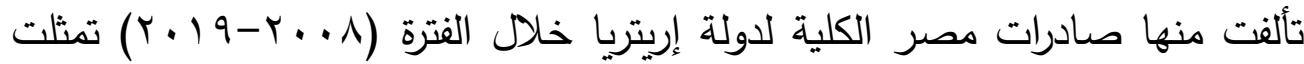
فى 1 مجموعات رئيسية بالاضافة إلى، استحوذت مجموعة "المنتجات الحيوانية

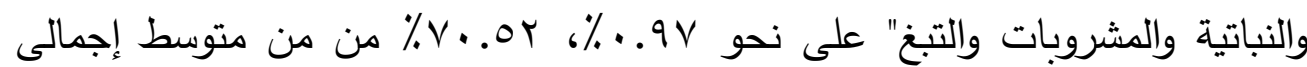
الصادرات المصرية الكلية من المجموعات السلعية للعالم، متوسط إجمالى الصادرات المصرية الكلية من المجموعات السلعية لدول القرن الأفريقى، يليها مجموعة المنتجات

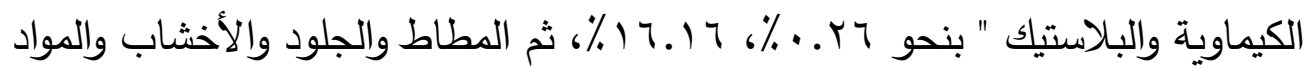

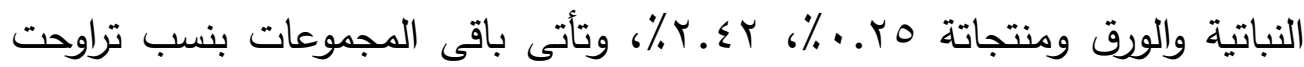

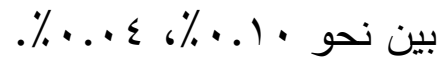

؟ - التوزيع السلعى لصادرات مصر الكلية لدولة الصومال بإستقراء بيانات جدولى (1، 0) تبين أن المجموعات السلعية الرئيسية التى تألفت منها

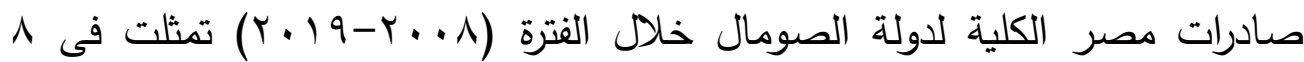
مجموعات رئيسية، استحوذت مجموعة " المنتجات الحيوانية والنباتية والمشروبات

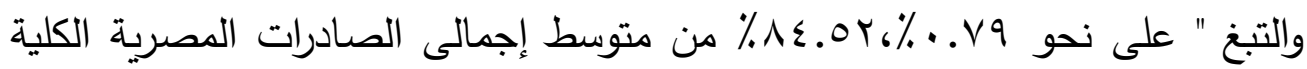


من المجموعات السلعية للعالم، متوسط إجمالى الصادرات المصرية الكلية من المجموعات السلعية لدول القرن الأفريقى، يليها مجموعة المنتجات الكيماوية

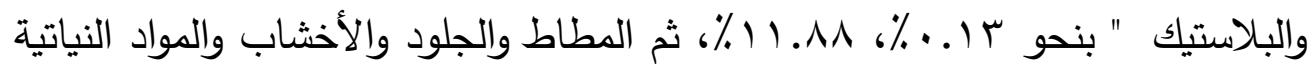
والورق ومنتجاتة ^^...٪، 19. 1\% وتأتى باقى المجموعات بنسب تراوحت بين $\% \cdot$.

جدول (؛): صادرات مصر الاجمالية من المجموعات السلعية لأريتريا بالمليون دولار خلال الفترة

\begin{tabular}{|c|c|c|}
\hline & & $\cdot(r \cdot 19-r \cdot \cdot \Lambda)$ \\
\hline$\%$ & المتوسط & 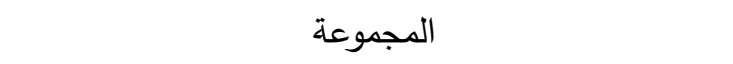 \\
\hline 70.52 & 45.84 & المنتجات الحيوانية والنباتية والمشروبات والتتخ \\
\hline 4.83 & 3.14 & الوقود والمنتجات البترولية ومنتجات الصناعات الاستخراجية \\
\hline 16.16 & 10.50 & المنتجات الكيماوية والبلاستيك \\
\hline 2.42 & 1.57 & المطاط والجلود والأخشاب والمواد النياتية والورق ومنتجاتة \\
\hline 0.19 & 0.12 & الخيوط والألياف النسيجية ومنتجات الغزل والنسيج والملابس \\
\hline 1.27 & 0.83 & مصنوعات الرخام والأحجار والخزف والزجاج والمواد المماتلة \\
\hline 3.63 & 2.36 & المنتجات المعدنية \\
\hline 0.99 & 0.64 & الألات والأجهزة الآلية والكهربائية ومعدات النقل وأجزائها \\
\hline 100.00 & 65.01 & الاجمالى \\
\hline
\end{tabular}

المصدر: حسبت من: www.comtrade.un.org

جدول (•): صادرات مصر الاجمالية من المجموعات السلعية للصومال بالمليون دولار خلال الفترة

\begin{tabular}{|c|c|c|}
\hline & & $\cdot(r+19-r+\cdots)$ \\
\hline$\%$ & المتوسط & 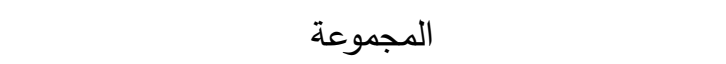 \\
\hline 84.52 & 37.14 & المنتجات الحيوانية والنناتية والمشروبات والتتخ \\
\hline 0.85 & 0.37 & الوقود والمنتجات البترولية ومنتجات الصناعات الاستخراجية \\
\hline 11.88 & 5.22 & المنتجات الكيماوية والبلاستيك \\
\hline 1.19 & 0.52 & المطاط والجلود والأخشاب والمواد النياتية والورق ومنتجاتة \\
\hline
\end{tabular}




\begin{tabular}{|c|c|c|}
\hline 0.72 & 0.32 & الخيوط والألياف النسيجية ومنتجات الغزل والنسيج والملابس \\
\hline 0.12 & 0.05 & مصنوعات الرخام والأحجار والخزف والزجاج والمواد المماتلة \\
\hline 0.31 & 0.14 & 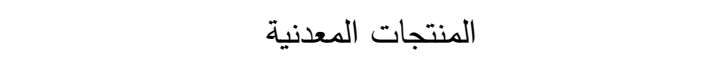 \\
\hline 0.40 & 0.18 & الألات والأجهزة الآلية والكهربائية ومعدات النقل وأجزائها \\
\hline 100.00 & 43.94 & الاجمالى \\
\hline
\end{tabular}

خامساً: التنافسية السلعية لدول القرن الأفريقى. فى هذا الجزء سيتم قياس مؤشرات التتافسية السلعية للصادرات المصرية فى دول القرن الأفريقى لقياس مدى اهمية الصادرات المصرية لدول القرن الافريقى: 1- التنافسية السلعية للصادرات المصرية لاولة جيبوتى: وفقا لما سبق ذكره فى ما يتعلق بالتوزيع السلعى للصادرات المصرية من المجموعات السلعية لدولة جيبوتى أشارت البيانات إلى استحواذ مجموعة المنتجات الحيوانية والنباتية والمشروبات والتبغ على حوالى اب٪ من الصادرات المصرية من المجموعات السلعية لدولة جيبوتى. وتضم هذه المجموعة گr سلعة أو مجموعة سلعية فرعية وفقا Trade Statistics for International business لتصنيف قاعدة بيانات development Database (UN Comtrade), Trade statistics for international business development (Trade map), المنتجات من الأصل أو المنشأ الحيوانى" منتجات الألبان، البيض، الطيور، العسل 
الطبيعى" على ؟ ؟ \% من الصادرات المصرية الكلية لجيبوتى من هذه المجموعة كما

$$
\text { يتضح من جدول (T). }
$$

جدول (؟): الأهمية النسبية للصادرات المصرية من الجبن واللبن الرايب لدولة جيبوتى خلال الفترة $\cdot(r+19-r+\Lambda)$

\begin{tabular}{|c|c|c|c|}
\hline$\%$ & 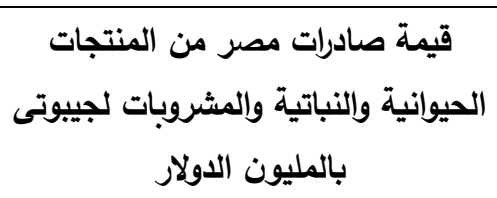 & قاللين الريب لجادرات مصر من الجين & 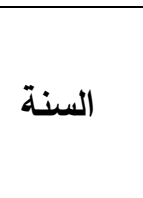 \\
\hline 5.8 & 5.14 & 0.30 & 2008 \\
\hline 40.2 & 10.81 & 4.34 & 2009 \\
\hline 4.8 & 9.60 & 0.46 & 2010 \\
\hline 8.6 & 7.14 & 0.61 & 2011 \\
\hline 10.2 & 6.50 & 0.66 & 2012 \\
\hline 10.8 & 5.74 & 0.62 & 2013 \\
\hline 2.6 & 6.96 & 0.18 & 2014 \\
\hline 7.4 & 8.69 & 0.64 & 2015 \\
\hline 5.7 & 10.16 & 0.58 & 2016 \\
\hline 5.2 & 15.40 & 0.80 & 2017 \\
\hline 4.0 & 14.77 & 0.60 & 2018 \\
\hline 4.8 & 12.62 & 0.60 & 2019 \\
\hline 9.2 & & & المتوسط \\
\hline
\end{tabular}

المصدر: حسبت من: www.comtrade.un.org

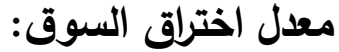

يتضح من بيانات الجدول (V) أن معدل اختراق الجبن واللبن الرايب فى سوق

جيبوتى بلـغ نحو هب . • وهو مرتفع مقارنـة بالدول المنافسـة مثل ايطاليا، الامـارات باستثناء فرنسا التى تتفوق فى اختراقها لسوق جيبوتى حيث بلـغ معدل الإختراق لها نحو ؟ ـ. • حيث تتفوق فرنسا فى انتاجها لمنتجات الألبان ومصنعاتها، بالإضافة إلى 
ضسف انتاج جيبوتى من منتجات الألبان وبالتالى ليس لها نشاط فى تصدير هذه المنتجات. السعر النسبي

يتضح من بيانات الجدول (V) تمتع مصر بميزة نسبية سعرية تنافسية مقارنة بالدول المنافسـة لها في تصدير الجبن واللبن الرايب حيث بلـغ السعر النسبي بين

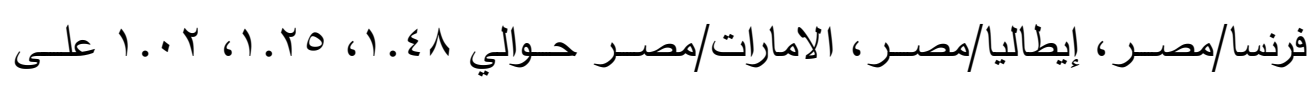
الترتيب، ووفقاً لبيانات هذا المؤشر يتضح وجود ميزة نسبية سعرية تتافسية لمصر في سوق جيبوتى مقارنة بالدول المنافسة لها. النصيب السوقي يلاحظ من جدول (v) أن النصيب السوقى للصادرات المصرية من الجبن واللبن الرايب لجيبوتى هى نغس مؤشرات معدل اختراق السوق لطبيعة أن تركيب مؤشر معدل اختراق السوق يتكون من انتاج وصادرات جيبوتى من الجبن واللبن الرايب، وهى ليس لها انتاج او صادرات تذكر · معدل النمو السنوي في كمية الصادرات بتقدير الاتجاه العام لكمية الصسادرات المصرية من الجبن واللبن الرايب لجيبوتى تبين أن معامـل الانحـدار في الدالـة الخطيـة يتتـاقص سـوياً بمقدار ع.9 طـن بمعـل

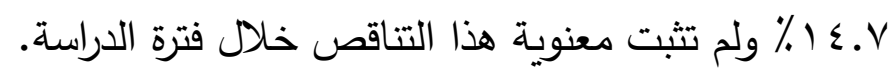


معامل عدم الاستقرار يتضـح من بيانـات الجدول (V) تذبذب الصـادرات المصرية مـن الجبن واللبن الرايب

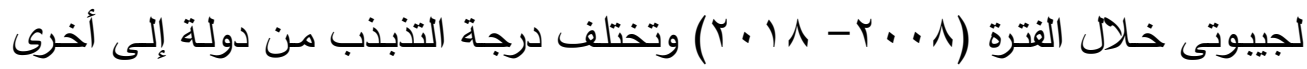
وفقاً لمعامل عدم الاستقرار حيث بلـغ في كل من مصر ، فرنسـا، إيطاليا، الإمـارات

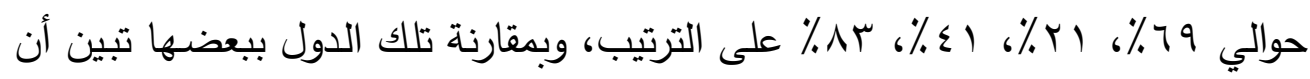
إيطاليا تأتى فى المرتبة الأولي في درجة الاستقرار في صادرات الجبن واللبن الرايب، في حين أن الإمارات، مصر تتميز بعدم الاستقرار فى صسادرات الجبن واللبن الرايب، وهى من المؤشرات التي يمكن أن تؤدي إلى ضعف المكانة التنافسية لمصر في سوق جيبوتى. 


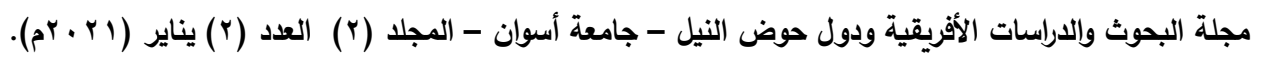

جدول(V): مؤشرات التنافس السلعى للصادرات المصرية من الجبن واللبن الرايب لاولة جييوتى

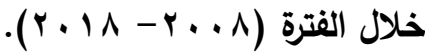

\begin{tabular}{|c|c|c|c|c|c|c|c|c|c|}
\hline 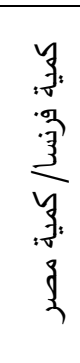 & 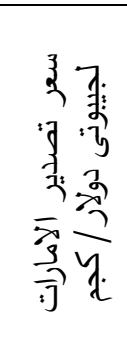 & 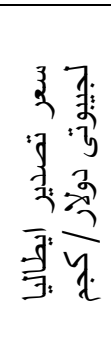 & 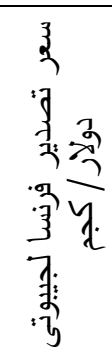 & 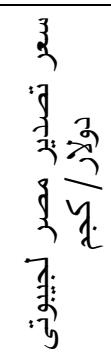 & 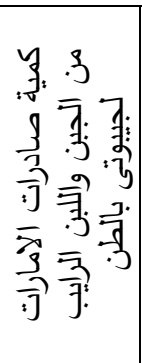 & 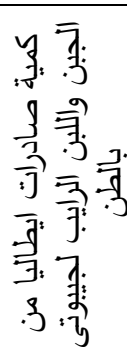 & 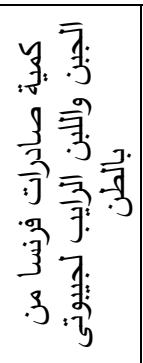 & 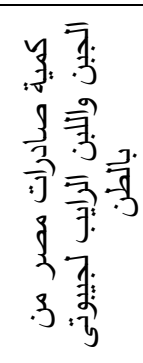 & \\
\hline 1.5 & 10294 & 4500 & 7095 & 3268 & 8.70 & 2.51 & 139.30 & 91.86 & 2008 \\
\hline 0.1 & 3960 & 5364 & 7247 & 4504 & 21.33 & 1.21 & 141.10 & 964.28 & 2009 \\
\hline 2.1 & 4147 & 5934 & 5516 & 4534 & 12.00 & 7.27 & 215.80 & 102.14 & 2010 \\
\hline 1.1 & 1753 & 6459 & 5895 & 3028 & 189.86 & 11.46 & 215.37 & 202.97 & 2011 \\
\hline 1.3 & 6388 & 5883 & 6537 & 4822 & 14.31 & 9.63 & 171.36 & 137.07 & 2012 \\
\hline 1.6 & 5167 & 6046 & 6990 & 5946 & 113.39 & 14.74 & 162.98 & 104.09 & 2013 \\
\hline 3.9 & 2772 & 4230 & 7537 & 5202 & 20.54 & 15.41 & 137.15 & 34.84 & 2014 \\
\hline 0.6 & 5228 & 4490 & 6648 & 3752 & 96.54 & 27.27 & 107.71 & 170.33 & 2015 \\
\hline 1.0 & 2258 & 4617 & 6452 & 4447 & 40.68 & 13.58 & 135.09 & 129.96 & 2016 \\
\hline 1.7 & 2461 & 5630 & 5722 & 5359 & 15.22 & 6.33 & 248.03 & 149.30 & 2017 \\
\hline 2.1 & 3365 & 7315 & 5369 & 5296 & 75.25 & 9.50 & 241.57 & 112.86 & 2018 \\
\hline 1.55 & 4345 & 5497 & 6455 & 4560 & 55 & 11 & 174 & 200 & المتوسط \\
\hline
\end{tabular}

تابع جدول (V):

\begin{tabular}{|c|c|c|c|c|c|c|c|c|c|c|c|c|}
\hline 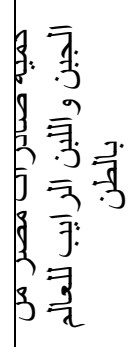 & 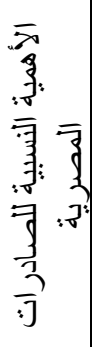 & 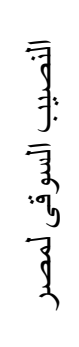 & 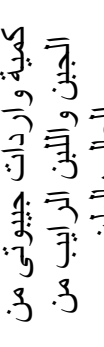 & 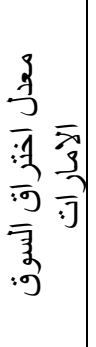 & $\begin{array}{l}\frac{3}{3} \\
\frac{1}{1} \\
\frac{19}{9} \\
\overline{3} \\
: 9 \\
03 \\
3\end{array}$ & 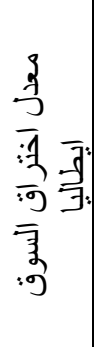 & $\begin{array}{l}\frac{3}{3} \\
\frac{1}{13} \\
\frac{9}{9} \\
\overline{3} \\
: 9 \\
9 \\
3\end{array}$ & 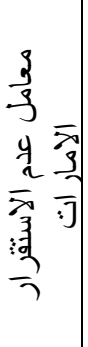 & $\begin{array}{l}3 \\
3 \\
y \\
y \\
2 \\
\overline{2} \\
3 \\
\frac{3}{3} \\
\frac{9}{7}\end{array}$ & 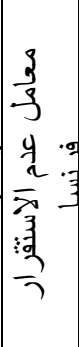 & $\begin{array}{l}3 \\
3 \\
3 \\
\frac{9}{2} \\
z \\
\frac{3}{3} \\
\frac{3}{7}\end{array}$ & \\
\hline 98.4 & 0.0 & 32. & 287 & 0.0 & 0.4 & 0.0 & 0.3 & 81 & 56 & 9 & 74 & 2008 \\
\hline 130. & 0.7 & 65. & 148 & 0.0 & 0.1 & 0.0 & 0.6 & 55 & 82 & 1 & 20 & 2009 \\
\hline 158. & 0.0 & 30. & 339 & 0.0 & 0.6 & 0.0 & 0.3 & 76 & 6 & 3 & 65 & 2010 \\
\hline
\end{tabular}




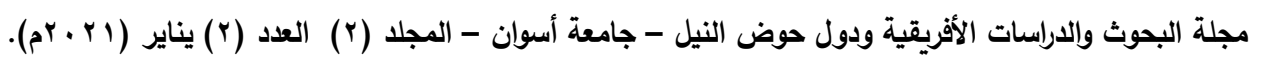

\begin{tabular}{|l|l|l|l|l|l|l|l|l|l|l|l|l|l|}
\hline & 179. & 0.1 & 32. & 623 & 0.3 & 0.3 & 0.0 & 0.3 & 27 & 31 & 3 & 22 & 2011 \\
\hline 75.1 & 0.1 & 40. & 335 & 0.0 & 0.5 & 0.0 & 0.4 & 73 & 2 & 1 & 40 & 2012 \\
\hline & 99.0 & 0.1 & 26. & 392 & 0.2 & 0.4 & 0.0 & 0.2 & 10 & 36 & 6 & 48 & 2013 \\
\hline 114. & 0.0 & 16. & 208 & 0.1 & 0.6 & 0.0 & 0.1 & 64 & 30 & 2 & 80 & 2014 \\
\hline 116. & 0.1 & 43. & 390 & 0.2 & 0.2 & 0.0 & 0.4 & 63 & 11 & 4 & 21 & 2015 \\
\hline 122. & 0.1 & 38. & 336 & 0.1 & 0.4 & 0.0 & 0.3 & 33 & 2 & 2 & 16 & 2016 \\
\hline 105. & 0.1 & 33. & 450 & 0.0 & 0.5 & 0.0 & 0.3 & 76 & 57 & 3 & 82 & 2017 \\
\hline 104. & 0.1 & 20. & 541 & 0.1 & 0.4 & 0.0 & 0.2 & 16 & 40 & 2 & 11 & 2018 \\
\hline 104. & $:$ & 34. & 489 & 0.1 & 0.4 & 0.0 & 0.3 & 83 & 41 & 2 & 69 & المتوس \\
\hline 118. & 0.1 & 34. & & & & & & & & & &
\end{tabular}




\section{الأهمية النسبية للصادرات}

يتضح من بيانات الجدول (V) أن الأهمية النسبية للصادرات المصرية من الجبن واللبن الرايب لجيبوتى لم تتعدى r. • ٪ من إجمالى الصادرات المصرية الكلية من الجبن واللبن الرايب. مما يشير إلى إنخفاض مستوى التمثيل المصرى لهذا المنتج فى سوق جييوتى. محددات المركز التنافسي لقياس أثر محددات المركز التتافسى على الصادرات المصرية من الجبن واللبن الرايب

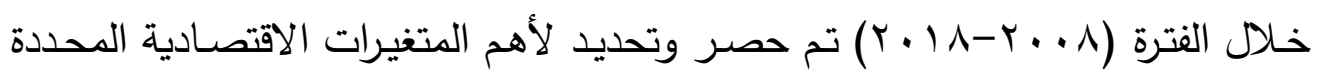
المركز التنافسى وتتمثل في كمية الصـادرات من الجبن واللبن الرايب للدولة المنافسة/ نظيـره المصـري (X ${ }^{X}$ )، سـعر تصـدير الجبن واللبن الرايـب للدولـة المنافسـة/ نظيـره المصـري (X $X_{2 i}$ )، معامـل عـدم الاسـتقرار فـي الصـادرات مـن الجبن واللـبن الرايـب المصرية أو الدول المنافسة (X X ) )، معدل اختراق أسواق الجبن واللبن الرايب لمصر أو الدول المنافسة (

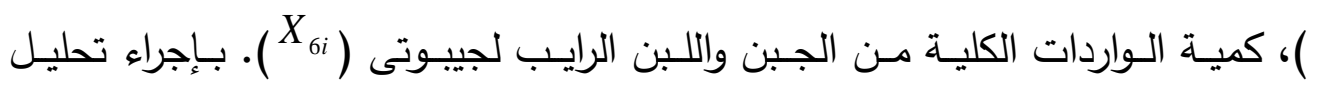
الانحدار المرحلي للمتغيرات الاقتصـادية السـابق الإثـارة إليها كمتغيرات مستقلة مـع الاستعانة بكميـة الصـادرات المصـرية مـن الجبن واللبن الرايب لجيبـتى بـالطن (Y) 
مجلة البحوث والدراسات الأفريقية ودول حوض النيل - جامعة أسوان - المجلد (r) العدد (r) يناير (اr +rم).

كمتغير تابع وذلك باستخدام الصور الرياضية المختلفة تبين أن أفضل النماذج الممثلة لهذه العلاقة هو النموذج الخطي التالي:

$$
\stackrel{\Lambda}{Y}=-531.04+69.73 \mathrm{X}_{1}+1022.2 \mathrm{X}_{11}+0.55 \mathrm{X}_{15}
$$

$$
(4.55)^{*} \quad(7.09)^{*} \quad(16.03)^{*}
$$

$$
\mathrm{R}^{-2}=0.99 \quad \mathrm{~F}=359.55^{*} \quad \mathrm{DW}=1.503
$$

حيث يشير X1 الى كمية الصادرات من الجبن واللبن الرايب لفرنسا/ مصر ، X11 الى معدل اختراق الصادرات المصرية من الجبن واللبن الرايب لسوق جيبوتى، X15 كمية واردات جيبوتى الكلية من الجبن واللبن الرايب. وباستبعاد المتغيرات المستقلة التي لا تتقق مع المنطق الإحصائي (كمية الصادرات من الجبن واللبن الرايب لفرنسا/ مصر ) تم التوصل إلى أفضل الصور الرياضية الخطية المعبرة عن تلك العلاقة ومتفقة مع المنطق الاقتصادي والإحصائي ووفقاً لمعنويـة كل من اختبار (T)، (F)، وهي على الثكل التالي:

$$
\begin{gathered}
\stackrel{\Lambda}{Y}=-259.77+515.31 \mathrm{X}_{11}+0.57 \mathrm{X}_{15} \\
(3.01)^{*} \quad(9.14)^{*} \\
\mathrm{R}^{-2}=0.96 \quad \mathrm{~F}=152.57^{*} \quad \mathrm{DW}=1.82
\end{gathered}
$$


حيث تبين منه خلو النموذج من مشاكل الارتباط الذاتي استتاداً إلى معامل - حurbin Watson ، معنوية معاملات المتغيرات المستقلة عند مستوي معنوي ا ... استتاداً إلى قيمة اختبار (T) لكل متغير ، معنويـة النموذج ككل عند مستوي معنوي ا ... استناداً إلى قيمـة اختبار (F) للنموذج، إيجابيـة إشـارة المتغيـران المستقلين (X اختراق الصادرات المصرية من الجبن واللبن الرايب لسوق جيبوتى، X جيبوتى الكلية من الجبن واللبن الرايب)، مما يعني أن تغيراً ايجابياً في هذان المتغيرين بنسبة ( ٪ يمكن أن يـؤدي إلى زيـادة الصـادرات المصـرية مـن الجبن واللبن الرايب

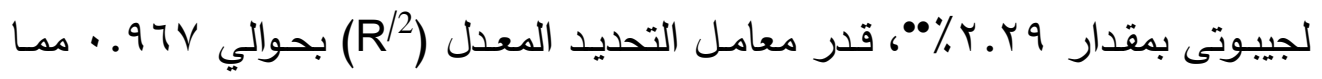
يعني أن حوالي \.9 ٪ من التغيرات في كمية الصسادرات المصرية من الجبن واللبن الرايب لجيبوتى إلى التغيرات في المتغيرات المستقلة موضع الدراسة. r - التنافسية السلعية للصادرات المصرية لدولة لأثيوبيا: وفقا لما سبق ذكره فى ما يتعلق بالتوزيع السلعى للصادرات المصرية من المجموعات السلعية لدولة أثيوبيا أشارت البيانات إلى استحواذ مجموعة المنتجات الحيوانية والنباتية • • تم حساب المرونـة أعتمادا على

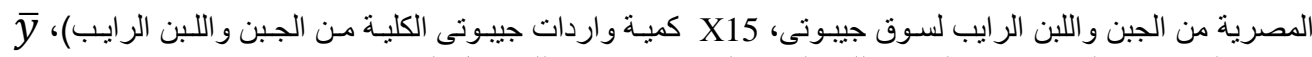

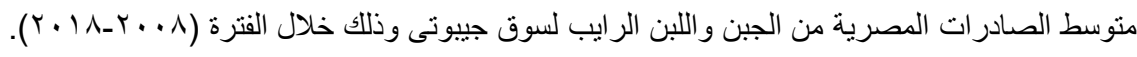


والمشروبات والتبغ على حوالى 1 ٪ من الصادرات المصرية من المجموعات السلعية لدولة اثيوبيا. وتضم هذه المجموعة ؟r سلعة أو مجموعة سلعية فرعية، واستحوذت مجموعة بذور دوار الثمس، وزيت بذرة القطن والقرطم سواء مكرر أو غير ولكن غير معدل كيميائياً " على ؟.^\% من الصادرات المصرية الكلية لأثيوبيا من هذه المجموعة

$$
\text { كما يتضح من جدول (^). }
$$

يتضح من بيانات الجدول (9) أن معدل اختراق مجموعة بذور دوار الثمس،

وزيت بذرة القطن والقرطم سـواء مكرر أو غير المصـرى فى سوق أثيوبيا بلـغن نحو 7 . . . وهو مرتفع مقارنة بالدول المنافسة مثل بلجيكا، إيطاليا، الامارات باستثناء تركيا التى تتفوق فى اختراقها لسوق أثيوبيا حيث بلغ معدل الإختراق لها نحو 17 .. وهو ما يعنى تفوق تركيا فى تصدير هذه السلعة واعتماد أثثوبيا على تغطية 7 ( ٪ من إحتياجها من هذه السلعة من الواردات التركية. حيث تجدر الاشارة هنا على انتاج أثيوبيا نحو \% \% من احتياجها من هذه السلعة.

جدول (^): الأهمية النسبية للصادرات المصرية من بذور دوار الثمس، وزيت بذرة القطن والقرطم

\begin{tabular}{|c|c|c|c|}
\hline$\%$ & الحيوانية والنباتية والمشروبات مصر من المنتجات لأثيوبيا & قيمة صادرات مصر من بذور دوار & السنة \\
\hline 0.65 & 10.18 & 0.07 & 2008 \\
\hline
\end{tabular}

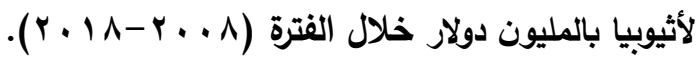




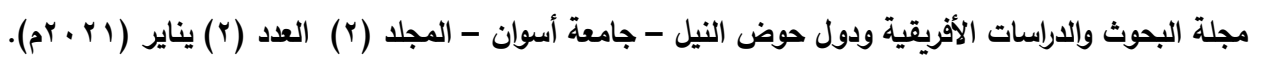

\begin{tabular}{|c|c|c|c|}
\hline 2.42 & 7.91 & 0.19 & $\mathbf{2 0 0 9}$ \\
\hline 0.24 & 12.25 & 0.03 & $\mathbf{2 0 1 0}$ \\
\hline 8.19 & 16.51 & 1.35 & $\mathbf{2 0 1 1}$ \\
\hline 3.70 & 2.59 & 0.10 & $\mathbf{2 0 1 2}$ \\
\hline 8.02 & 8.33 & 0.67 & $\mathbf{2 0 1 3}$ \\
\hline 7.72 & 9.77 & 0.75 & $\mathbf{2 0 1 4}$ \\
\hline 7.14 & 26.63 & 1.90 & $\mathbf{2 0 1 5}$ \\
\hline 2.46 & 18.72 & 0.46 & $\mathbf{2 0 1 6}$ \\
\hline 23.30 & 20.63 & 4.81 & $\mathbf{2 0 1 7}$ \\
\hline 26.52 & 10.76 & 2.85 & $\mathbf{2 0 1 8}$ \\
\hline $\mathbf{8 . 2 2}$ & $\mathbf{1 3 . 1 2}$ & $\mathbf{1 . 2}$ & b \\
\hline
\end{tabular}

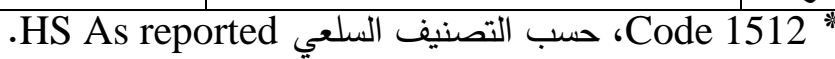

المصدر: حسبت من: www.comtrade.un.org

يتضح من بيانات الجدول (9) تمتع مصر بميزة نسبية سعرية تنافسية مقارنة

بالدول المنافسة لها في تصدير مجموعة بذور دوار الثمس، وزيت بذرة القطن والقرطم سـواء مكـرر أو غيـر حيـث بــن السـعر النسـبي بـين بلجيكا/مصـر ، إيطاليا/مصـر ،

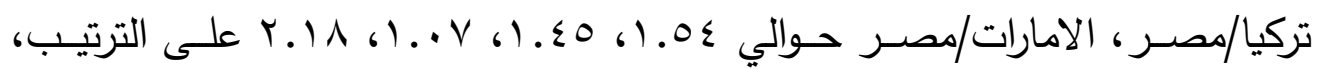
ووفقاً لبيانات هذا المؤشر يتضـح وجود ميزة نسبية سعرية تنافسية لمصر في سوق أثيوبيا مقارنة بالدول المنافسة لها.

\section{النصيب السوقي}

يلاحظ من جدول (9) أن النصيب السوقى للصـادرات المصـرية من مجموعـة

بذور دوار الثمس، وزيت بذرة القطن والقرطم سواء مكرر أو غير لأثيوبيا بلـغ نحو

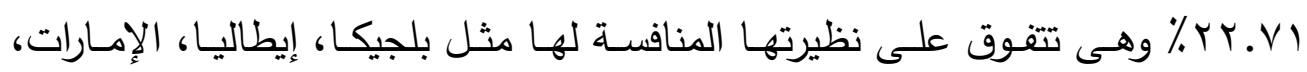


مجلة البحوث والدراسات الأفريقية ودول حوض النيل - جامعة أسوان - المجلد (r) العدد (r) يناير ( Y · rم).

باستثناء تركيا حيث تستحوذ على r₹ ٪ من السوق الأثيوبى من مجموعة بذور دوار

الثمس، وزيت بذرة القطن والقرطم سواء مكرر أو غير. 
جدول(9): مؤشرات التنافس السلعى للصادرات المصرية من بذور دوار الثمس، وزيت بذرة القطن

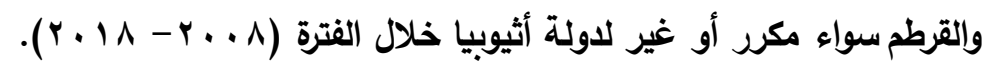

\begin{tabular}{|c|c|c|c|c|c|c|c|c|c|c|c|c|c|c|c|}
\hline $\begin{array}{c}3 \\
\vdots \\
\text { 求 } \\
\frac{3}{3} \\
\vdots \\
\xi\end{array}$ & 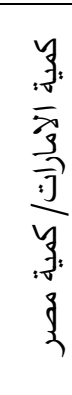 & 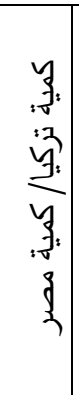 & 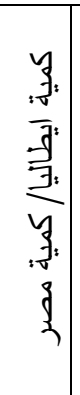 & 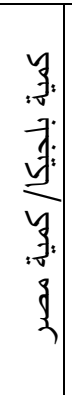 & 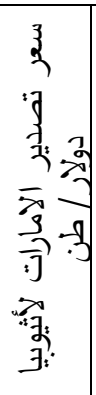 & 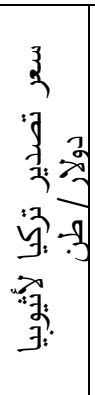 & 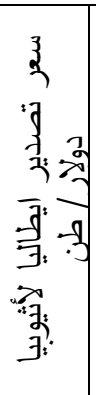 & 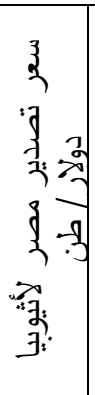 & 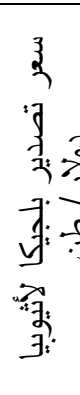 & 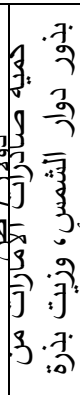 & 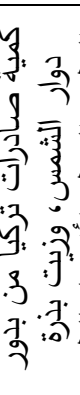 & 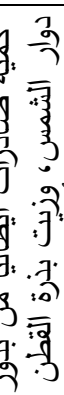 & 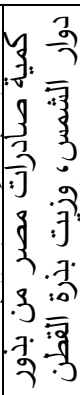 & 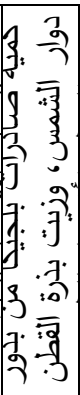 & \\
\hline 1. & 0. & 0. & 0. & 0. & 23 & 12 & 31 & 11 & 20 & 10 & 28. & 3. & 56. & 2. & 20 \\
\hline 1. & 0 . & 0. & 0. & 0. & 22 & 11 & 13 & 12 & 13 & 20 & 3. & 13 & 15 & 75 & 20 \\
\hline 1. & 1. & 36 & 0. & 0. & 21 & 13 & 15 & 11 & 16 & 27 & 98 & 9. & 26. & 21 & 20 \\
\hline 4. & 0. & 2. & 0. & 0. & 20 & 17 & 20 & 16 & 70 & 2. & 23 & 37 & 80 & 0 . & 20 \\
\hline 1. & 0. & 12 & 0. & 0. & 88 & 16 & 17 & 13 & 16 & 60 & 89 & 38 & 72. & 9. & 20 \\
\hline 1. & 0 . & 4. & 0. & 0. & 11 & 15 & 18 & 13 & 17 & 49 & 22 & 54 & 51 & 2. & 20 \\
\hline 1. & 0. & 2. & 0. & 0. & 12 & 12 & 15 & 12 & 18 & 1. & 12 & 40 & 62 & 2. & 20 \\
\hline 0. & 0. & 2. & 0. & 0. & 13 & 11 & 16 & 12 & 11 & 67 & 40 & 11 & 14 & 12 & 20 \\
\hline 1. & 0. & 5. & 0. & 0. & 15 & 11 & 14 & 98 & 12 & 72 & 24 & 55 & 46 & 88 & 20 \\
\hline 1. & 0. & 1. & 0. & 0. & 12 & 10 & 17 & 11 & 11 & 5. & 46 & 17 & 42 & 28 & 20 \\
\hline 1. & 0. & 1. & 0. & 0. & 27 & 10 & 15 & 11 & 12 & 14 & 31 & 18 & 25 & 18 & 20 \\
\hline 1. & о. & 6. & $\mathbf{0}$. & 0. & 26 & 13 & 17 & 12 & 20 & 42 & 20 & 36 & 10 & 57 & الدة \\
\hline
\end{tabular}




\section{تابع جدول (9):}

\begin{tabular}{|c|c|c|c|c|c|c|c|c|c|c|c|c|c|c|c|c|c|}
\hline 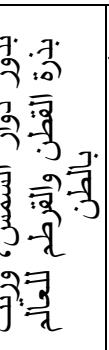 & 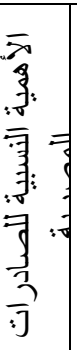 & $\begin{array}{c}\overline{3} \\
\text { 哥: } \\
\overline{3} \\
\text { :鸟 } \\
3 \\
\xi\end{array}$ & 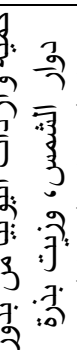 & 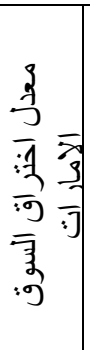 & $\begin{array}{l}3 \\
3 \\
: 1 \\
\overline{59} \\
\overline{3} \\
: 9 \\
: 3 \\
y\end{array}$ & 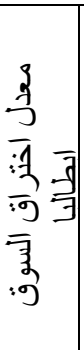 & $\begin{array}{l}\frac{3}{3} \\
: 13 \\
\overline{9} \\
\overline{3} \\
: 9 \\
\xi \\
\xi\end{array}$ & 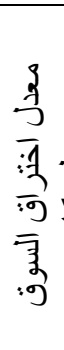 & 龒 & $\begin{array}{l}3 \\
3 \\
3 \\
9 \\
2 \\
\frac{7}{3} \\
3 \\
3 \\
7\end{array}$ & 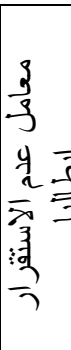 & $\begin{array}{l}3 \\
3 \\
3 \\
9 \\
\frac{1}{2} \\
\frac{3}{3} \\
\frac{3}{7}\end{array}$ & $\begin{array}{l}3 \\
3 \\
3 \\
9 \\
2 \\
\frac{2}{3} \\
3 \\
\frac{3}{7} \\
7\end{array}$ & $\begin{array}{l}7 \\
3 \\
7 \\
3\end{array}$ & 诖 & $\begin{array}{l}\exists \\
\exists\end{array}$ & \\
\hline $\begin{array}{c}3490 \\
?\end{array}$ & $\begin{array}{l}0 . \\
16\end{array}$ & $\begin{array}{l}1 . \\
70\end{array}$ & $\begin{array}{c}330 \\
5\end{array}$ & $\begin{array}{l}0.0 \\
012\end{array}$ & 0. & $\begin{array}{c}0.0 \\
0 n\end{array}$ & $\begin{array}{c}0 . \\
0 .\end{array}$ & $\begin{array}{c}0.0 \\
0.02\end{array}$ & $\begin{array}{c}15 \\
0\end{array}$ & 70 & 83 & 11 & 14 & 2. & 1 & 2 & 20 \\
\hline $\begin{array}{c}3490 \\
2\end{array}$ & $\begin{array}{l}0 . \\
15\end{array}$ & $\begin{array}{r}99 \\
2 \\
\end{array}$ & 157 & $\begin{array}{r}0.0 \\
042\end{array}$ & $\begin{array}{l}0 . \\
0 . \\
0 .\end{array}$ & 0.0 & $\begin{array}{l}0 . \\
\Omega 3\end{array}$ & $\begin{array}{c}0.0 \\
158\end{array}$ & 73 & 92 & 40 & 19 & $\begin{array}{c}89 \\
7 \\
7\end{array}$ & 1. & 1 & 1 & 20 \\
\hline $\begin{array}{c}2202 \\
2\end{array}$ & $\begin{array}{l}0 . \\
12\end{array}$ & $\begin{array}{c}1 . \\
07\end{array}$ & $\begin{array}{c}249 \\
1\end{array}$ & $\begin{array}{l}0.0 \\
041\end{array}$ & $\begin{array}{l}0 . \\
15\end{array}$ & $\begin{array}{c}0.0 \\
n 1\end{array}$ & $\begin{array}{l}0 . \\
0 . \\
\text { no }\end{array}$ & $\begin{array}{l}0.0 \\
032\end{array}$ & 40 & 15 & 64 & 79 & 7 & 2. & 1 & 1 & 20 \\
\hline 2320 & 3. & 20 & $\begin{array}{c}393 \\
7\end{array}$ & $\begin{array}{l}0.0 \\
002\end{array}$ & 0. & 0.0 & 0. & 0.0 & 93 & 87 & 27 & 93 & 10 & 1. & 1 & 1 & 20 \\
\hline 5814 & $\begin{array}{c}0 . \\
12\end{array}$ & $\begin{array}{r}3 . \\
60 \\
\end{array}$ & 197 & $\begin{array}{c}0.0 \\
076\end{array}$ & $\begin{array}{l}0 . \\
11\end{array}$ & 0.0 & $\begin{array}{c}0 . \\
0 . \\
م\end{array}$ & $\begin{array}{r}0.0 \\
\Omega 12\end{array}$ & 74 & 45 & 14 & 90 & 78 & $\begin{array}{l}0 . \\
7\end{array}$ & 1 & 1 & 20 \\
\hline $\begin{array}{c}3503 \\
7\end{array}$ & 1. & $\begin{array}{r}17 \\
1\end{array}$ & 300 & $\begin{array}{r}0.0 \\
050\end{array}$ & $\begin{array}{l}0 . \\
27\end{array}$ & $\begin{array}{l}0.0 \\
06\end{array}$ & $\begin{array}{l}0 . \\
0 . \\
06\end{array}$ & $\begin{array}{r}0.0 \\
0 \times 3\end{array}$ & 18 & 13 & 47 & 49 & 95 & $\begin{array}{c}0 . \\
0\end{array}$ & 1 & 1 & 20 \\
\hline $\begin{array}{c}2618 \\
6\end{array}$ & $\begin{array}{l}2 . \\
38\end{array}$ & $\begin{array}{r}27 \\
8\end{array}$ & $\begin{array}{c}224 \\
1\end{array}$ & $\begin{array}{l}0.0 \\
002\end{array}$ & 0. & 0.0 & 0. & 0.0 & 96 & 48 & 1 & 52 & 96 & 1 & 1 & 1 & 20 \\
\hline $\begin{array}{c}2100 \\
7\end{array}$ & $\begin{array}{c}7 . \\
\text { ก6 }\end{array}$ & $\begin{array}{r}21 \\
6\end{array}$ & $\begin{array}{c}685 \\
?\end{array}$ & $\begin{array}{r}0.0 \\
\mathrm{O} / 2\end{array}$ & $\begin{array}{l}0 . \\
26\end{array}$ & $\begin{array}{c}0.0 \\
08\end{array}$ & $\begin{array}{c}0 . \\
\text { no }\end{array}$ & $\begin{array}{c}0.0 \\
078\end{array}$ & 16 & 48 & $\begin{array}{c}16 \\
0\end{array}$ & 7 & 48 & $\begin{array}{c}0 . \\
1\end{array}$ & 0 & 1 & 20 \\
\hline $\begin{array}{c}2435 \\
1\end{array}$ & $\begin{array}{l}1 . \\
01\end{array}$ & $\begin{array}{l}9 . \\
10\end{array}$ & 507 & $\begin{array}{c}0.0 \\
056\end{array}$ & $\begin{array}{l}0 . \\
10\end{array}$ & $\begin{array}{c}0.0 \\
\mathrm{n}\end{array}$ & $\begin{array}{c}0 . \\
03\end{array}$ & $\begin{array}{r}0.0 \\
060\end{array}$ & 11 & 23 & 16 & 75 & 7 & $\begin{array}{l}1 . \\
5\end{array}$ & 1 & 1 & 20 \\
\hline $\begin{array}{c}2911 \\
0\end{array}$ & $\begin{array}{r}14 \\
7 \\
\end{array}$ & $\begin{array}{r}29 \\
0 \\
\end{array}$ & $\begin{array}{c}143 \\
60\end{array}$ & $\begin{array}{r}0.0 \\
0 \text { ח }\end{array}$ & $\begin{array}{c}0 . \\
22\end{array}$ & $\begin{array}{l}0.0 \\
01\end{array}$ & $\begin{array}{c}0 . \\
20\end{array}$ & $\begin{array}{r}0.0 \\
125\end{array}$ & 92 & 31 & 67 & 98 & $\begin{array}{c}16 \\
0 \\
\end{array}$ & $\begin{array}{l}1 . \\
1\end{array}$ & 1 & 1 & 20 \\
\hline $\begin{array}{c}2653 \\
5\end{array}$ & $\begin{array}{l}9 . \\
51\end{array}$ & $\begin{array}{r}17 \\
0\end{array}$ & $\begin{array}{c}140 \\
56\end{array}$ & $\begin{array}{c}0.0 \\
066\end{array}$ & $\begin{array}{l}0 . \\
11\end{array}$ & $\begin{array}{c}0.0 \\
\text { חn\& }\end{array}$ & $\begin{array}{c}0 . \\
11\end{array}$ & $\begin{array}{c}0.0 \\
\text { nח8 }\end{array}$ & 85 & 20 & 66 & 2 & 84 & $\begin{array}{l}2 . \\
1\end{array}$ & 0 & 1 & 20 \\
\hline 3049 & $\begin{array}{l}3 . \\
77\end{array}$ & $\begin{array}{r}22 \\
7\end{array}$ & 522 & $\begin{array}{l}0.0 \\
\Omega 1\end{array}$ & 0. & 0.0 & 0. & 0.0 & $\begin{array}{c}68 \\
8\end{array}$ & $\begin{array}{r}44 \\
7\end{array}$ & $\begin{array}{c}54 \\
\cap\end{array}$ & $\begin{array}{r}77 \\
3 \\
\end{array}$ & $\begin{array}{r}15 \\
65\end{array}$ & 2. & 1 & 1 & المت \\
\hline
\end{tabular}




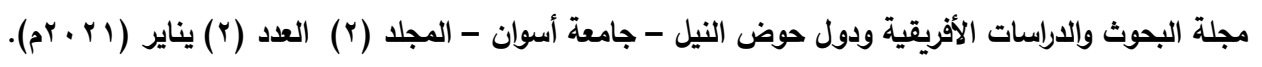

معدل النمو السنوي في كمية الصادرات

بتقدير الاتجاه العام لكمية الصـادرات المصرية من مجموعة بذور دوار الشمس، وزيت بذرة القطن والقرطم سواء مكرر أو غير لأثيوبيا تبين أنها تتزايد بمقدار Y. Y طن

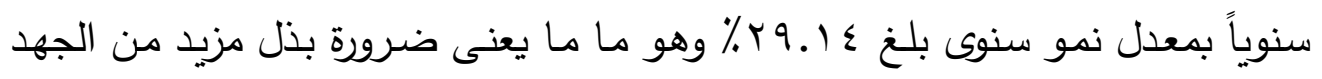
لتذليل المعوقات التى من سأنها زيادة الصادرات المصرية من هذه المجموعة.

$$
\stackrel{\Lambda}{Y}=-750.2+29.2 \mathrm{X}_{1}
$$

$$
\mathrm{R}^{2}=0.53 \quad \mathrm{~F}=10.35^{*}
$$

معامل عدم الاستقرار

يتضـح من بيانـات الجدول (9) تذبذب الصـادرات المصرية من مجموعـة بذور دوار الثمس، وزيت بذرة القطن والقرطم سواء مكرر أو غير لأثيوبيا خلال الفترة (1 ... -

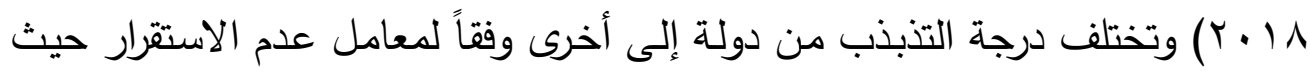

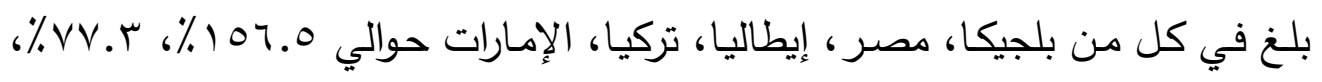

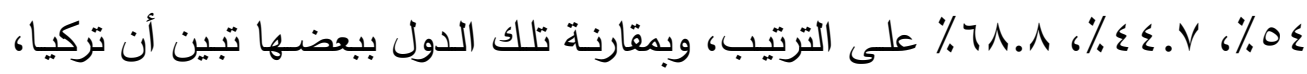
إيطاليا تأتى فى المرتبة الأولي والثانية في درجة الاستقرار في صادرات مجموعة بذور دوار الثـمس، وزيت بذرة القطن والقرطم سـواء مكرر أو غير لأثيوبيا، في حين أن 
بلجيكا، مصـر، الإمـارات تتميز بعدم الاستقرار فى صـادرات مجموعـة بذور دوار الثمس، وزيت بذرة القطن والقرطم سواء مكرر أو غير لأثيوبيا، وهى من المؤشرات التي يمكن أن تؤدي إلى ضعف المكانة التنافسية لمصر في سوق أثيوبيا. الأهمية النسبية للصادرات يتضح من بيانات الجدول (9) أن الأهمية النسبية للصادرات المصرية من مجموعة بذور دوار الثمس، وزيت بذرة القطن والقرطم سواء مكرر أو غير لأثيوبيا بلغت من من إجمالى الصادرات المصرية الكلية من مجموعة بذور دوار الثمس، وزيت بذرة القطن والقرطم سواء مكرر أو غير. مما يثير إلى إنخفاض مستوى التشثل المصرى لهذا المنتج فى سوق أثيوبيا. مددات المركز التنافسي لقياس أثر محددات المركز التتافسى على الصادرات المصرية من مجموعة بذور دوار الثمس، وزيت بذرة القطن والقرطم سواء مكرر أو غير لأثيوبيا خلال الفترة (^... 1 ( † ) تم حصر وتحديد لأهم المتغيرات الاقتصادية المحدة المركز التتافسى وتتمثل في كمية الصادرات من مجموعة بذور دوار الثمس، وزيت بذرة القطن والقرطم سواء مكرر أو غير للدولة المنافسة/ نظيره المصري (X) )، سعر تصدير مجموعة بذور دوار الثمس، وزيت بذرة القطن والقرطم سواء مكرر أو غير للدولة المنافسة/ نظيره المصري (Xi $X_{2 i}$ ) معامل عدم الاستقرار في الصادرات من مجموعة بذور دوار الثمس، 
وزيت بذرة القطن والقرطم سواء مكرر أو غير لمصر أو الدول المنافسة ( ${ }^{X}$ )، معدل اختراق أسواق مجموعة بذور دوار الثمس، وزيت بذرة القطن والقرطم سواء مكرر أو غير لمصر أو الدول المنافسة ( ${ }^{\left.X_{4 i}\right) ، ~ ك م ي ة ~ ا ل ص ـ ا د ر ا ت ~ ا ل م ص ر ي ة ~ ا ل ك ل ي ة ~ م ن ~ م ج م و ع ة ~}$ بـذور دوار الثـمس، وزيــت بذرة القطن والقرطم سـواء مكرر أو غيـر ( الواردات الكلية من مجموعة بذور دوار الثمس، وزيت بذرة القطن والقرطم سواء مكرر أو غير لأثيوبيا ( ${ }^{X_{6 i}}$ ) بإجراء تحليل الانحدار المرحلي للمتغيرات الاقتصادية السابق الإثـارة إليها كمتغيرات مستقلة مع الاستعانة بكمية الصـادرات المصرية من مجموعة بذور دوار الثمس، وزيت بذرة القطن والقرطم سواء مكرر أو غير لأثيوبيا بالطن (Y) كمتغير تابع وذلك باستخدام الصور الرياضية المختلفة تبين أن أفضل النماذج الممثلة لهذه العلاقة هو النموذج الخطي التالي: $\stackrel{\Lambda}{Y}=-496.2+13206.6 \mathrm{X}_{15}+0.12 \mathrm{X}_{20}$

$$
\mathrm{R}^{-2}=0.96 \quad \mathrm{~F}=144.94 * \quad \mathrm{DW}=2.81
$$

حيـث يشـير X15 الـى معـدل اختـراق الصـادرات المصـرية مـن مجموعـة بـذور دوار الثـمس، وزيــت بذرة القطن والقرطح سـواء مكرر أو غيـر لسـوق أثيوبيـا، Xميـة 
مجلة البحوث والدراسات الأفريقية ودول حوض النيل - جامعة أسوان - المجلد (r) العدد (r) يناير (اr +rم).

واردات أثيوبيا الكلية من مجموعة بذور دوار الثمس، وزيت بذرة القطن والقرطم سواء

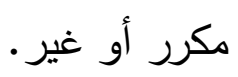

Durbin- وتبـين خلـو النــوذج مـن مشـاكل الارتبـاط الـذاتي اسـتناداً إلـى معامـل Watson معنوية معاملات المتغيرات المستقلة عند مستوي معنوي ا +.. استتاداً إلى قيمة اختبار (T) لكل متغير ، معنوية النموذج ككل عند مستوي معنوي ... استناداً إلى قيمـة اختبار (F) للنموذج، إيجابية إثـارة المتغيران المستقلين (X15 الى معدل اختراق الصادرات المصرية من مجموعة بذور دوار الثمس، وزيت بذرة القطن والقرطم سواء مكرر أو غير لسوق أثيوبيا، X20 كمية واردات أثيوبيا الكلية من مجموعة بذور دوار الشمس، وزيت بذرة القطن والقرطم سواء مكرر أو غير، مما يعني أن تغيراً ايجابياً في هذان المتغيرين بنسبة ( بمكن أن يؤدي إلى زيـادة الصـادرات المصـرية مـن مجموعة بذور دوار الشمس، وزيت بذرة القطن والقرطم سواء مكرر أو غير لأثيوبيا بمقدار rع. 1\%، قدر معامل التحديد المعدل (R/2) بحوالي 97 . . مما يعني أن حوالي ج \% مـن التغيـرات في كميـة الصـادرات المصـرية مـن مجموعـة بـور دوار الثـمس، وزيت بذرة القطن والقرطم سواء مكرر أو غير لأثيوبيا إلى التغيرات في المتغيرات المستقلة موضع الدراسة. 
استهدف هذا البحث دراسـة وتحليل مؤشرات القدرة التنافسية للصـادرات المصرية فى أسـواق دول القـرن الأفريقى، والتقدير القياسـي لأهـم محددات القدرة التتافسية على صـادرات تلك السلـع، ونسب تأثير كل محدد على صـادرات تلك السلـع، الأمـر الذي يساعد في وضـع إستراتيجية لصـادرات مصر من هذه السلع تساعد على زيادة قدرتها التتافسية. وتوصلت الدراسة إلى ما يلى:

- استحوذت صادرات مصر الكلية لدول القرن الإفريقي من مجموعة "المنتجات الحيوانية والنباتية والمشروبات والتبغ" على نحو هץ.Y\% من متوسط إجمالى صادرات مصر الكلية للعالم من المجموعات السلعية، يليها مجموعة" المطاط والجلود والأخشاب والمواد النياتية والورق ومنتجاتة " بنحو VV. . . . - استحوذت صادرات مصر الكلية لدولة جيبوتي، أريتريا، الصومال من مجموعة

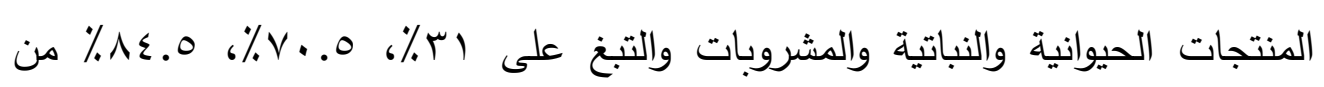
الصادرات المصرية الكلية لكل دولة على الترتيب. - أن النصيب السوقى لصادرات مصر من الجبن واللبن الرايب فى السوقى الجيبوتى بلغ نحو هץ\% متفوقة بذلك على الدول المنافسة مثل إيطاليا، الامارات، كما تبين تمتع مصر بميزة نسبية سعرية تنافسية مقارنة بالدول المنافسة لها في تصدير الجبن واللبن 
- أن زيادة معدل اختراق الصادرات المصرية من الجبن واللبن الرايب لسوق جيبوتى، وكمية واردات جيبوتى الكلية من الجبن واللبن الرايب بنسبة ( بمكن أن يؤدي إلى ئ زيادة الصادرات المصرية من الجبن واللبن الرايب لجيبوتى بمقدار و ج.Y٪. - أن معدل اختراق مجموعة بذور دوار الثمس، وزيت بذرة القطن والقرطم سواء مكرر أو غير المصرى فى سوق أثيوبيا بلغ نحو 7 ... وهو مرتفع مقارنة بالدول المنافسة مثل بلجيكا، إيطاليا، الامارات باستثناء تركيا التى تتفوق فى اختراقها لسوق أثيوبيا، أشارت النتائج إلى أن مصر لها ميزة نسبية سعرية تتافسية مقارنة بالدول المنافسة لها بلجيكا، إيطاليا، تركيا، الامارات في تصدير مجموعة بذور دوار الثمس، وزيت بذرة القطن والقرطم سواء مكرر أو غير، وأن النصيب السوقى للصادرات المصرية من مجموعة بذور دوار الثمس، وزيت بذرة القطن والقرطم سواء مكرر أو غير لأثيوبيا بلغ نحو اYY.V\% وهى تتفوق على نظيرتها المنافسة لها مثل بلجيكا، إيطاليا، الإمارات، باستثناء تركيا حيث تستحوذ على rع ٪ من السوق الأثيوبى. - أن زيادة معدل اختراق الصادرات المصرية من مجموعة بذور دوار الثمس، وزيت بذرة القطن والقرطم سواء مكرر أو غير لسوق أثثوبيا، وكمية واردات أثيوبيا الكلية من مجموعة بذور دوار الثمس، وزيت بذرة القطن والقرطم سواء مكرر أو غير بحوالى ) 


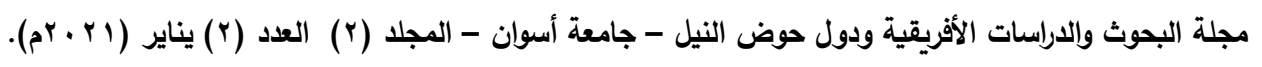

يمكن أن يؤدي إلى زيادة الصادرات المصرية من مجموعة بذور دوار الثمس، وزيت

بذرة القطن والقرطم سواء مكرر أو غير لأثيوبيا بمقدار بــــ.

وفى ضوء ما سبق من نتائج توصى الاراسة بالأتى:

ا- الاستفادة من الجاليات المصرية ومكاتب التثثيل التجارى بدول القرن الافريقى

لذليل المعوقات التى تواجه الصادرات المصرية بأسواق هذه الدول.

r- العمل على إقامة صيخ بديلة مبتكرة للتبادل التجارى مع دول القرن الأفريقى خاصة

فى ظل الموارد الطبيعية الخام بتلك الدول.

المراجع:

ا ـ حازم الببلاوي ، نظرية التجارة الدولية، دار المعارف، الإسكندرية ، 1941 ،

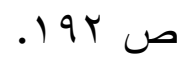

r. عبد الباقي موسى الثايب، "دراسة اقتصادية للصادرات المصرية من البرتقال

ومؤشرات تنافسيته فى أسواقه الرئيسية"، مجلة الزقازيق للبحوث الزراعية، مجلد

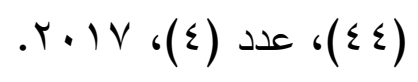

r. كمال زريق، التنافسية في الجزائر ضمن مقتضيات التنافسية الدولية كمؤشر

للأداء المتميز، المؤتمر العلمي الدولي حول الأداء المتميز للمنظمات

$$
\text { والحكومات، جامعات ورفله، } 9 \text { مارس } 0 \text {. . r. }
$$




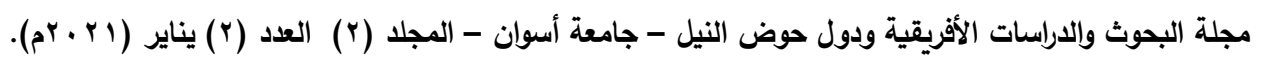

4. Michele's corporation and Lionel's Foundation. (2003). "Competitiveness", counsel of Economic Analysis, Paris, P.13.

5. World Economic Forum, The Global Competitiveness Report 2013-2014, 2012-2013 www.albankaldawli.org/dataandresearch/

6. www.comtrade.un.org

7. www.trademap.org 